\title{
Motor Function in School-Aged Children with Attention-Deficit/Hyperactivity Disorder in Korea
}

\author{
Hyunjin Cho', Seokyeon $\mathrm{Ji}^{1}$, Sungho Chung ${ }^{2}$, Meesun Kim¹, and Yoo-Sook Joung ${ }^{3 凶}$ \\ ${ }^{1}$ Sensory Integration Toward Social and Occupational Being (SISO), Seoul, Republic of Korea \\ ${ }^{2} \mathrm{BH}$ Hospital, Busan, Republic of Korea \\ ${ }^{3}$ Department of Psychiatry, Samsung Medical Center, Sungkyunkwan University School of Medicine, Seoul, Republic of Korea
}

\begin{abstract}
Objective Motor function critically influences daily activities and academic performance. We compared motor function in schoolaged children with Attention-Deficit/ Hyperactivity Disorder (ADHD) to that of normal children.

Methods Participants were 58 children with ADHD [ 51 males, 7 females; mean age 9 years 6 months \pm 2 years 0 months (SD)] and 70 normal controls [ 56 males, 14 females; mean age 9 years 2 months \pm 1 years 7 months (SD)]. We assessed motor function with the Bruininks-Oseretsky Test of Motor Proficiency, Second Edition.

Results The ADHD group had a significantly lower total motor composite score $(\mathrm{t}=-9.32, \mathrm{p}<0.001)$ than that of the control group. Standard scores of four motor-area composites such as fine manual control $(t=-3.76, p<0.001)$, manual coordination $(t=-6.87, p<0.001)$, body coordination ( $\mathrm{t}=-7.14, \mathrm{p}<0.001)$, and strength and agility $(\mathrm{t}=-8.54, \mathrm{p}<0.1)$ were significantly lower in the ADHD group than those in the control group. Among the subtests, scores on fine motor precision, fine motor integration, manual dexterity, bilateral coordination, balance, running speed and agility, and strength were significantly lower in the ADHD group than those in the controls, whereas upper-limb coordination was not significantly different between the groups.

Conclusion School-aged children with ADHD in Korea had significantly lower motor function compared to that of controls. Thus, it is suggested that appropriate target intervention for motor function is important in children with motor impairment in addition to pharmacotherapy or psychosocial therapy for improving the core symptoms.

Psychiatry Investig 2014;11(3):223-227
\end{abstract}

Key Words Motor function, Attention-deficit hyperactivity disorder, Bruininks-Oseretsky Test of Motor Proficiency, Second Edition.

\section{INTRODUCTION}

Attention-deficit hyperactivity disorder (ADHD) is a neurodevelopmental disorder with an early onset, typically before 7 years of age. ADHD is characterized by hyperactivity, inattention, and impulsivity and has a prevalence of 5-12\% worldwide in school-age children, 1 and $6.5 \%$ in Korea. ${ }^{2}$ ADHD studies are divided broadly into those examining the social and cultural components affecting $\mathrm{ADHD}$ characteristics and symptoms and those examining the neurodevelopmental dysfunction in patients with ADHD. ${ }^{2,6-8}$ Recently ADHD studies have shifted increasingly toward the neurodevelopmental perspec-

Received: May 3, 2013 Revised: June 6, 2013

Accepted: June 13, 2013 Available online: July 21, 2014

$\triangle$ Correspondence: Yoo-Sook Joung, $\mathrm{MD}, \mathrm{PhD}$

Department of Psychiatry, Samsung Medical Center, Sungkyunkwan University School of Medicine, 81 Irwon-ro, Gangnam-gu, Seoul 135-710, Republic of Korea Tel: +82-2-3410-0930, Fax: +82-2-3410-0050, E-mail: yschoung@skku.edu

(c) This is an Open Access article distributed under the terms of the Creative Commons Attribution Non-Commercial License (http://creativecommons.org/licenses/bync/3.0) which permits unrestricted non-commercial use, distribution, and reproduction in any medium, provided the original work is properly cited. tive, applying the findings that Children with ADHD show increasing difficulties in neurodevelopmental functioning, resulting in problems in learning and interpersonal relationships, compared to those in normally developing children. ${ }^{3}$

A number of studies have explicitly addressed the relationship between ADHD and motor deficits. ${ }^{4}$ According to previous studies, $30-70 \%$ of children with ADHD have motor control problems, which may contribute to their problems in neurobehavioral development. ${ }^{4,5}$ Motor impairment predisposes school-aged children to problems in social competence and academic achievement. ${ }^{4}$ Children and adolescents with motor problems may struggle with many issues such as the desire to avoid physical activity, obesity, lack of concentration, low self-esteem and school performance and reduced efficacy in social relationships. ${ }^{6,7}$ Moreover, motor problems are strong predictors of poor self-esteem. ${ }^{8}$ Children suffering impairments with bike riding, dressing, tying shoelaces, and/or writing may also experience problems with social participation, peer relationships, and adaptations needed during daily life. ${ }^{9}$ 
Therefore, early detection of motor delay and remediation decreases feelings of incompetency, inadequacy, depression, frustration, and anxiety in children with ADHD and prevents long-term negative effects on social development and academic achievement.?

For these reasons, researchers have accurate, substantial assessments of the neurodevelopmental motor functions of school-aged children with ADHD, but little research has been conducted on the motor function of such children in Korea.

In fact, The children with ADHD used to be intervened mainly focusing on hyperactivity, inattention, and impulsivity. Motor function is relevant to improve main symptoms, daily living skills, and academic performance of children with ADHD in clinical practice. Despite this consideration, evaluation and intervention of motor function is not generalized for children with $\mathrm{ADHD}$ in Korea. Children with $\mathrm{ADHD}$ who have motor difficulties or lack motor skills have been misunderstood as having a poor attitude, being lazy, pretending to be indifferent, and teasing others. Consequently, there is a need for standardized motor function measures of ADHD and this has become a rationale for targeted intervention. This trial will be expected to contribute to improve the overall development of children with ADHD.

The Bruininks-Oseretsky Test of Motor Proficiency, Second Edition (BOT-2) has been demonstrated to be a reliable measure of motor proficiency and is among the most frequently used assessments for evaluating and discriminating motor function in children. ${ }^{10}$

We evaluated motor proficiencies in school-aged children with ADHD and a control group to identify specific neuromotor developmental characteristics in the ADHD group for the purpose of gaining insight into appropriate interventions for children with ADHD.

\section{METHODS}

\section{Participants}

The participants were 58 children with ADHD [51 males, 7 females; mean age, 9 years 6 months \pm 2 years 0 months (SD), range 6 years 5 months to 13 years 7 months] and 70 normal controls [56 males, 14 females; mean age, 9 years 2 months \pm 1 years 7 months (SD), range 6 years 11 months to 12 years 4 months] (Table 1). This study was performed from August 2008 to May 2011. The ADHD group was recruited from the Department of Psychiatry, Samsung Medical Center, Sungkyunkwan University School of Medicine. Two experienced child and adolescent psychiatrists diagnosed these children based on the ADHD criteria of the Diagnostic and Statistical Manual of Mental Disorders, Fourth Edition, Text Revision $(\mathrm{DSM}-\mathrm{IV}-\mathrm{TR})^{11}$ and administered the Korean Kiddie-Schedule for Affective Disorders and Schizophrenia-Present and Lifetime Version ${ }^{12}$ to confirm ADHD and to identify any comorbidities. Learning disorders were diagnosed with the DSM-IVTR by assessment using intelligence and academic achievement tests. Among the participants, 25 had ADHD without any comorbidities, eight had depression, seven had Asperger's Disorder, six had Learning Disorder, six had Children Emotional Disorder, four had Oppositional Deficient Disorder, and two had Tic Disorder. Mental retardation and psychotic and other seizure disorders were ruled out in this study. At the time of assessment, 24 of the children were taking medication (14 were taking methylphenidate and 10 atomoxetine) for symptoms related to ADHD. Thirty-four children were not taking any medications.

We recruited the control group from six elementary schools in Seoul by proportional stratified sampling and screened potential participants with the Korean ADHD Rating Scale (KARS), ${ }_{13}^{13}$ which was completed by parents and teachers. We excluded any children suspected of having possible ADHD (i.e., K-ARS scores $\geq 19$, as reported by parents, and $\geq 17$, as reported by teachers). Children with school adjustment problems, learning problems, or physical illnesses that affected motor function were also excluded by a teacher's report. The Institutional Review Board approved this study, and the parents gave informed consent for their children to participate.

\section{Measures}

We used the BOT-2 to assess participant motor function. ${ }^{14}$

Table 1. Clinical characteristics of the participants

\begin{tabular}{llcccc}
\hline \multicolumn{1}{c}{ Characteristics } & & ADHD $(\mathrm{N}=58)$ & Control $(\mathrm{N}=70)$ & $\mathrm{t} / \chi^{2}$ & 0.87 \\
\hline Age (year) & & $9.55(1.98)^{*}$ & $9.20(1.67)^{*}$ & 0.28 & 0.11 \\
Gender & Male & 51 & 56 & 14 & $<2$ \\
& Female & 7 & $7.82(5.39)^{*}$ & $<0.01$ \\
K-ARS & Parents & $25.44(9.22)^{*}$ & $4.90(5.64)^{*}$ & $<0.01$ \\
& Teacher & $21.72(8.20)^{*}$ & & -1.64 & 0.11 \\
Presence of co-morbid & Yes & 33 & & \\
& No & 25 & & \\
\hline
\end{tabular}

*mean (SD). K-ARS: Korean-ADHD Rating Scale, ADHD: attention-deficit hyperactivity disorder 
This is an individually administered test using engaging, goaldirected activities to measure a wide array of motor skills in individuals aged 4-21 years. This standardized test consists of 53 items and four motor-area composite scores (fine manual control, manual coordination, body coordination, and strength and agility). The four motor-area composites are each comprised of two of eight subtests relating to aspects of motor function (fine manual control=fine motor precision and fine motor integration, manual coordination=manual dexterity and upper-limb coordination, body coordination=bilateral coordination and balance, and strength and agility=running speed and strength and agility). The 53-item raw score is scaled to a standard score according to age norms. Finally, the four standard score sums become the total motor composite, which is an overall motor proficiency score. Internal consistency, reliability, test-retest reliability and inter-rater reliability of the BOT-2 is moderate to strong $(>0.80) .{ }^{15}$ The BOT- 2 content validity, internal structure, and correlations with other motor performance measures are strong $(\mathrm{r}=0.80){ }^{10}$

Occupational therapists used authenticated test kits and booklets to administer the BOT-2. Each test took 60-90 minutes, depending on the participant's speed.

\section{Statistical analysis}

We used the BOT-2 T-scores for analysis. We used the chisquare and t-tests to evaluate differences in clinical variables between the two groups and assessed differences in standard and total motor composite scores. We used regression to rule out an age effect. Statistical analyses were performed using SPSS version 18.0 (SPSS, Inc., Chicago, IL, USA). A p-value< 0.05 was considered significant.

\section{RESULTS}

There were no significant differences in mean age $(\mathrm{p}=0.28)$ or gender ratio $(\mathrm{p}=0.11)$ between the two groups. The K-ARS scores reported by parents and teachers differed significantly $(p<0.01)$ between the two groups. Table 1 summarizes the clinical characteristics of the participants.

The ADHD group had significantly lower mean standard scores on fine motor control $(\mathrm{t}=-3.76, \mathrm{p}<0.001)$, manual coordination $(\mathrm{t}=-6.87, \mathrm{p}<0.001)$, body coordination $(\mathrm{t}=-7.14, \mathrm{p}<$ $0.001)$, strength and agility $(\mathrm{t}=-8.54, \mathrm{p}<0.01)$, and total motor composite score $(t=-9.32, \mathrm{p}<0.001)$ compared to those of the controls (Table 2, Fig. 1). Among the subtests, the ADHD group had significantly lower scores on fine motor precision $(\mathrm{t}=-3.84, \mathrm{p}<0.001)$, fine motor integration $(\mathrm{t}=-2.10, \mathrm{p}<0.05)$, manual dexterity $(\mathrm{t}=-11.78, \mathrm{p}<0.001)$, bilateral coordination $(\mathrm{t}=-3.56, \mathrm{p}<0.01)$, balance $(\mathrm{t}=-8.90, \mathrm{p}<0.001)$, running speed and agility $(\mathrm{t}=-4.84, \mathrm{p}<0.001)$, and strength $(\mathrm{t}=-9.39, \mathrm{p}<0.001)$. However upper-limb coordination $(\mathrm{t}=-0.97, \mathrm{p}=0.337)$ did not differ significantly between the two groups. No age effect was observed in the groups ( $\mathrm{p}=-0.58)$.

\section{DISCUSSION}

We compared motor function in school-aged children with ADHD as assessed by the BOT-2 and compared the results to those of a control group in Korea. The ADHD group demonstrated significantly lower motor function than that of the controls in all categories of fine manual control, manual coordination, body coordination, and strength and agility, indicating that children with ADHD have greater physical movement

Table 2. BOT-2 standard scores and total motor composite in the ADHD and control groups

\begin{tabular}{cccc}
\hline & ADHD mean (SD) & Control mean (SD) & t \\
\hline Fine manual control & $47.86(9.34)$ & $53.40(6.84)$ & $-3.76^{* * *}$ \\
Fine motor precision & $15.14(4.59)$ & $17.86(3.10)$ & $-3.84^{* * *}$ \\
Fine motor integration & $13.64(4.02)$ & $15.07(3.69)$ & $-2.10^{*}$ \\
Manual coordination & $44.52(9.91)$ & $55.50(8.18)$ & $-6.87^{* * *}$ \\
Manual dexterity & $13.21(4.64)$ & $21.81(3.38)$ & $-11.78^{* * *}$ \\
Upper-limb coordination & $12.28(4.90)$ & $13.04(4.10)$ & -0.97 \\
Body coordination & $41.48(9.08)$ & $52.81(8.81)$ & $-7.14^{* * *}$ \\
Bilateral coordination & $14.50(4.84)$ & $17.13(3.82)$ & $-3.56^{* *}$ \\
Balance & $8.72(4.02)$ & $15.20(4.16)$ & $-8.90^{* * *}$ \\
Strength and agility & $43.10(10.38)$ & $56.93(7.81)$ & $-8.54^{* *}$ \\
Running speed and agility & $14.91(4.19)$ & $18.36(3.85)$ & $-4.84^{* * *}$ \\
Strength & $10.46(4.14)$ & $17.33(4.10)$ & $-9.39^{* * *}$ \\
Total motor composite & $43.12(8.37)$ & $59.17(10.67)$ & $-9.32^{* * *}$ \\
\hline
\end{tabular}

${ }^{*} \mathrm{p}<0.05,{ }^{* *} \mathrm{p}<0.01,{ }^{* * *} \mathrm{p}<0.001$ by independent sample t-test. ADHD: attention-deficit hyperactivity disorder, BOT-2: Bruininks-Oseretsky Test of Motor Proficiency, Second Edition 


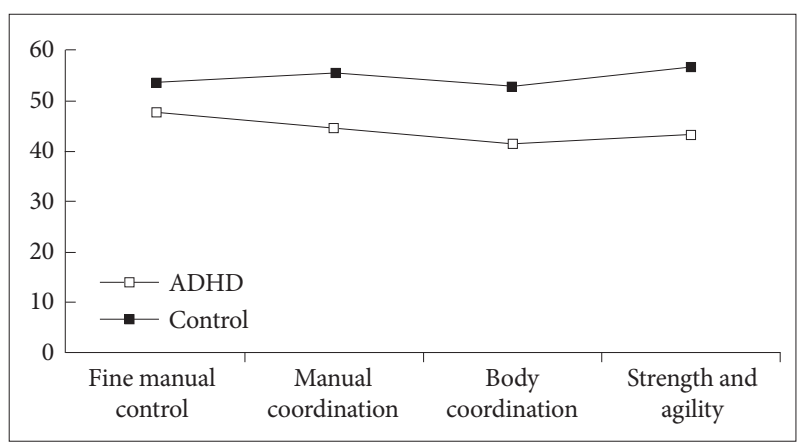

Figure 1. Standard scores in four motor categories in the ADHD and control groups. ADHD: attention-deficit hyperactivity disorder.

difficulties than those of typical children. These results support previous studies showing that children with ADHD usually have problems with deficits in dexterity, fine motor coordination, motor overflow, neurologically subtle signs, and difficulties with appropriate reactions during complex tasks and poor balance. ${ }^{16,17}$ Children with ADHD showed lower performance on subtests of manual dexterity and balance and strength. Muscle tone, equilibrium reaction maturity, establishing a midline, postural control, lateralization, proximal stability, sequential development of grasping and pinching, integration of primitive reflex, and reciprocity of the flexor-extensors are essential to achieve these movements, and integration of these motor factors is the foundation of purposeful movement in daily life. ${ }^{18}$

Before neuroimaging studies actively addressed the issue, researchers reported that ADHD appeared to be a phenomenon of developmental problems, particularly dysfunction of the connection between the lower region of the frontal and prefrontal subdivisions and subcortical brain regions, which are reportedly relevant to reduced motor and/or cognitive functions in children with ADHD. In addition, prefrontal lobe region dysfunctions can produce impulsivity and/or hyperactivity and self-control problems associated with executive function, and this region also plays a role inhibiting undesired or inappropriate motor behaviors..$^{19}$ According to recent neuroimaging studies, not only the prefrontal lobe, but also the basal ganglia, affect goal-directed movements in children with ADHD. ${ }^{20}$ Furthermore, the frontal-striatal circuit affects such motor control. ${ }^{21,22}$ Because the subcortical areas contribute to eye-hand coordination, body awareness, posture, balance, muscle tone, and stability against gravity, subcortical dysfunction affects cortical areas related to organization, selfcontrol, learning ability, abstract and logical thinking, and confidence. ${ }^{23}$ In addition, studies have reported differences in the sizes of the total brain, cerebellum, and basal ganglia between ADHD and normal groups. ${ }^{24}$ In particular, such studies consistently report a reduced vermis cerebellar size as an ADHD structural abnormality. The vermis cerebella controls head posture, eye movements, and overall posture by interacting with the vestibular and proprioceptive systems. Dysfunction of this region makes neck and body control, postural stability and eye movements difficult, leading to impaired eye-hand coordination and effortful physical movements. ${ }^{16}$

Results on the upper-limb coordination subtest were not significantly different between the two groups. The mean score on the upper limb coordination is relatively lower than score on other subsets in a control group. The reason why the score on the upper-limb coordination subtest was not significantly different between the two groups may be related with the items of upper-limb coordination subset. The items of the upper-limb coordination subset are composed with throwing, catching, one hand dribbling, and alternating of tennis ball. Usually, there is no curriculum in elementary lower grades that the students do not have a experience handling the tennis ball in P.E. class. ${ }^{25}$ Little experience with tennis ball in normal control may be influencing on difficulty performing the items of upper- limb coordination. Further investigations must follow to clarify variables that affected these results.

A therapeutic approach is suggested to mature subcortical areas and to increase and recover motor functions via a taskoriented approach that focuses on subcortical activation to integrate underlying motor factors in patients with $\mathrm{ADHD}{ }^{26}$ As one of these therapeutic frameworks, a sensory processing and sensory integration approach can help to increase postural reactions, bilateral integration, eye movement, and balance. ${ }^{27}$ Improved subcortical function can affect higher cortical functions, such as organization, self-control, learning ability, abstract thinking and logical power, and confidence, as mentioned previously.

Human performance on a task is comprised of personal factors, environmental factors, and task factors. ${ }^{28}$ Therefore, modifying environmental and task factors is as important as increasing directed motor function. Successfully addressing poor motor proficiency, which affects learning and daily life at home and school, requires parents, teachers, and medical professionals to exchange detailed information and also requires specific support strategies correlated with personalenvironmental-task factors. For example, if a child has difficulty sitting still during class, sitting on a therapeutic ball or sitting with a therapeutic cushion on their chair should facilitate the child's use of the erector spinous muscles. This physical activity intervenes in the individual's motor function and helps increase their attention to tasks ${ }^{29}$ during class. Thus, interdisciplinary cooperation of parents, teachers, and medical professionals should be helpful for understanding the difficulties of children with ADHD and supporting them during task performance.

Despite previous research reporting that clumsiness and 
motor difficulties in early-school-aged children with ADHD disappear or improve with growth, 30 We found no significant differences due to age, suggesting that a child with motor difficulties would persistently have problems as they grow older. Therefore, rather than expecting natural maturity to address motor skill issues, appropriate therapeutic interventions are necessary.

Some limitations of this study should be discussed. First, we did not consider medications. The effects of methylphenidate include short-term increases in behavioral control and cognitive function and improved interpersonal relationships. ${ }^{21}$ We recommend controlling for the effects of this medication in future studies when comparing ADHD and control groups. Second, the ADHD group was recruited from a particular medical center; thus, it was difficult to generalize overall motor proficiency in the children with ADHD. Third, the BOT-2 has not been standardized in a Korean population, although Asian Americans were included in the original version. Fourth, Learning Disorder, Asperger's Disorder and Oppositional Defiant Disorder might be motor dysfunction variables.

We investigated motor function in school-aged children with ADHD in Korea by means of a norm-referenced assessment, and it was confirmed that children with ADHD have poor motor skills compared to those in controls. In addition, brain domains correlated with low subtest scores such as coordination, balance and strength conformed to the domains revealed in previous neuroimaging studies. Based on these results, teachers and parents who point to the attitude or behavior problems of children with ADHD have a better opportunity to understand these children's daily lives. Furthermore, proper treatment for motor problems in children with ADHD could improve their performance quality, self-esteem, and social development.

\section{REFERENCES}

1. Polanczyk G, de Lima MS, Horta BL, Biederman J, Rohde LA. The worldwide prevalence of ADHD: a systematic review and metaregression analysis. Am J Psychiatry 2007;164:942-948.

2. Yang SJ, Cheong S, Hong SD. Prevalence and correlates of attention deficit hyperactivity disorder: school-based mental health services in Seoul. J Korean Neuropsychiatr Assoc 2006;45:69-76.

3. Wilson PH. Practitioner review: approaches to assessment and treatment of children with DCD: an evaluative review. J Child Psychol Psychiatry 2005;46:806-823.

4. Kooistra L, Crawford S, Dewey D, Cantell M, Kaplan BJ. Motor correlates of ADHD: contribution of reading disability and oppositional defiant disorder. J Learn Disabil 2005;38:195-206.

5. Tseng MH, Henderson A, Chow SM, Yao G. Relationship between motor proficiency, attention, impulse, and activity in children with ADHD. Dev Med Child Neurol 2004;46:381-388.

6. Venetsanou F, Kambas A, Aggeloussis N, Serbezis V, Taxildaris K. Use of the Bruininks-Oseretsky Test of Motor Proficiency for identifying children with motor impairment. Dev Med Child Neurol 2007;49:846-848.
7. Gwynne K, Blick B. Motor performance checklist for 5-year-olds: a tool for identifying children at risk of developmental co-ordination disorder. J Paediatr Child Health 2004;40:369-373.

8. Skinner RA, Piek JP. Psychosocial implications of poor motor coordination in children and adolescents. Hum Mov Sci 2001;20:73-94.

9. Fliers E, Vermeulen S, Rijsdijk F, Altink M, Buschgens C, Rommelse N, et al. ADHD and poor motor performance from a family genetic perspective. J Am Acad Child Adolesc Psychiatry 2009;48:25-34.

10. Johnson BA, MacWilliams BA, Carey JC, Viskochil DH, D’Astous JL, Stevenson DA. Motor proficiency in children with neurofibromatosis type 1. Pediatr Phys Ther 2010;22:344-348.

11. American Psychiatric Association. Diagnostic and Statistical Manual Disorders, Text Revision, Fourth Edition. Washington, DC: American Psychiatric Association; 2000.

12. Kim YS, Cheon KA, Kim BN, Chang SA, Yoo HJ, Kim JW, et al. The reliability and validity of Kiddie-Schedule for Affective Disorders and Schizophrenia-Present and Lifetime Version- Korean version (K-SADSPL-K). Yonsei Med J 2004;45:81-89.

13. Kim YS, So YK, Noh JS, Choi NK, Kim SJ, Koh YJ. Normative data on the Korean ADHD Rating Scales (K-ARS) for parents and teacher. J Korean Neuropsychiatr Assoc 2003;42:352-359.

14. Deitz JC, Kartin D, Kopp K. Review of the Bruininks-Oseretsky Test of Motor Proficiency, Second Edition (BOT-2). Phys Occup Ther Pediatr 2007;27:87-102.

15. Bruininks RH, Bruininks BD. Bruninks-Oseretsky Test of Motor Proficiency. 2nd Edition. Minnesota: AGS Publishing; 2005.

16. Stray LL, Stray T, Iversen S, Ruud A, Ellertsen B, Tonnessen FE. The Motor Function Neurological Assessment (MFNU) as an indicator of motor function problems in boys with ADHD. Behav Brain Funct 2009;5: 22.

17. Fliers E, Rommelse N, Vermeulen SH, Altink M, Buschgens CJ, Faraone SV, et al. Motor coordination problems in children and adolescents with ADHD rated by parents and teachers: effects of age and gender. J Neural Transm 2008;115:211-220.

18. Case-Smith J, Allen AS, Pratt PN. Occupational Therapy for Children. 4th Edition. St Louis: Mosby; 2000.

19. Bush G. Attention-deficit/hyperactivity disorder and attention networks. Neuropsychopharmacology 2010;35:278-300.

20. Qiu A, Crocetti D, Adler M, Mahone EM, Denckla MB, Miller MI, et al. Basal ganglia volume and shape in children with attention deficit hyperactivity disorder. Am J Psychiatry 2009;166:74-82.

21. Stray LL, Stray T, Iversen S, Ruud A, Ellertsen B. Methylphenidate improves motor functions in children diagnosed with Hyperkinetic Disorder. Behav Brain Funct 2009;5:21.

22. Gogtay N, Giedd J, Rapoport JL. Brain development in healthy, hyperactive, and psychotic children. Arch Neurol 2002;59:1244-1248.

23. Ayres AJ. What is Sensory Integrative Dysfunction? In: Ayres AJ, Author. Sensory Integration and the Child. LA: Western Psychological Services, 2005, p.47-62.

24. Castellanos FX, Acosta MT. The neuroanatomy of attention deficit/hyperactivity disorder. Rev Neurol 2004;38(Suppl 1):S131-S136.

25. Lesson Data-Subject Lists. Available at: http://www.edunet4u.net/teacher/search/search.do. Accessed March 1, 2013.

26. Niemeijer AS, Smits-Engelsman BC, Schoemaker MM. Neuromotor task training for children with developmental coordination disorder: a controlled trial. Dev Med Child Neurol 2007;49:406-411.

27. Bundy AC, Lane SJ, Fisher AG. Sensory Integration: Theory and Practice. Philadelphia: F.A. David Company; 2000.

28. Fisher AG. Assessment of Motor and Process Skills. 5th Edition. Colorado: Three Star Press; 2003.

29. Smith AL, Hoza B, Linnea K, McQuade JD, Tom M, Vaughn AJ, et al. Pilot physical activity intervention reduces severity of ADHD symptoms in young children. J Atten Disord 2013;17:70-82.

30. Hamilton SS. Evaluation of clumsiness in children. Am Fam Physician 2002;66:1435-1440. 